\title{
Complete Replacement of Nitrite With a Lactobacillus fermentum on the Quality and Safety of Chinese Fermented Sausages
}

\author{
Yuning $\mathrm{Xu}^{1}$ and Yinglian Zhu ${ }^{1,2 *}$ \\ ${ }^{1}$ College of Food Science and Engineering, Qingdao Agricultural University, Qingdao, China, ${ }^{2}$ Qingdao Special Food \\ Research Institute, Qingdao, China
}

OPEN ACCESS

Edited by:

Gongliang Zhang,

Dalian Polytechnic University, China

Reviewed by:

Małgorzata Karwowska,

University of Life Sciences of Lublin

Poland

Hatice Yazgan,

Cukurova University, Turkey

${ }^{*}$ Correspondence:

Yinglian Zhu

cjs52002@163.com

Specialty section:

This article was submitted to

Food Microbiology,

a section of the journal

Frontiers in Microbiology

Received: 02 May 2021

Accepted: 12 July 2021

Published: 04 August 2021

Citation:

Xu Y and Zhu Y (2021) Complete

Replacement of Nitrite With

a Lactobacillus fermentum on the Quality and Safety of Chinese

Fermented Sausages.

Front. Microbiol. 12:704302. doi: 10.3389/fmicb.2021.704302
This study investigated the positive effects of complete replacement of nitrite with a Lactobacillus fermentum on the quality and safety of Chinese fermented sausages, and evaluated the risk of this strain. The effects of the strain on $\mathrm{pH}$, color, nitrite, thiobarbituric acid reactive substances (TBARS), total volatile basenitrogen (TVB-N), metmyoglobin (Met-Mb), biological amines, free amino acid content, and sensory index have been studied. The results revealed that the strain reduced the $\mathrm{pH}$ of the sausages, which reduced the risk of food-borne pathogens, and accelerated the acidification and gelation process. The inoculation of the strain produced pink color similar to $50 \mathrm{mg} / \mathrm{kg}$ nitrite, significantly reducing the residual risk of nitrite in the sausages. In addition, the strain effectively improved quality and nutrition of the sausages through preventing fat oxidation, protein decomposition, and myoglobin oxidation and increasing free amino acid content. The harmful biogenic amines species of the treated sample were reduced, although the tyramine contents were higher than the control, and the contents of the two groups were all far below the specified limit (800 mg/kg). The sensory analysis showed that the strain enhanced the taste, flavor, sourness, and overall acceptability of the sample sausages. Therefore, replacing nitrite completely with the strain $L$. fermentum could be a potential strategy to produce healthier and safer acceptable sausages through decreasing the risk of nitrite and improving nutrition and quality of the sausages.

Keywords: nitrite, Lactobacillus fermentum, fermented sausages, biological amines, thiobarbituric acid reactive substances, total volatile basenitrogen, metmyoglobin

\section{INTRODUCTION}

In food process, specific food additives are often added to prevent corruption and extend the shelf life of the foods. However, the residual of some chemical additives will threaten human health, and they might also form toxic compounds due to the chemical reaction between the reactants (Molognoni et al., 2019). Hence, the development of natural and harmless food additives has become research hotspots in food industry. The natural biopreservatives are ideal natural food preservatives, which are safe, nontoxic, and efficient and have no negative effects. However, there are fewer natural microbial preservatives that can be used in the meat industry, and in-depth explorations are needed. 
Chinese fermented sausages have unique flavor and rich nutrition, so they are very popular among people. However, naturally fermented sausages are easily contaminated by bacteria and have a short shelf life. Usually, certain food additives are added in the process of naturally fermented sausages to extend the shelf life. Among them, nitrite is often used in the process because it has color development ability, antioxidant activity, and antibacterial effects. However, the products of protein degradation during meat storage would react with nitrite to produce N-nitrosamine (Drabik-Markiewicz et al., 2011), which has carcinogenic effects to humans. As people pay more and more attention to health, it is very urgent to develop natural preservatives that are harmless to human health in the meat industry.

Lactic acid bacteria (LAB), as a kind of probiotics, are often used as starters for foods, such as sausages and yogurts. A previous report indicated that the $\mathrm{LAB}$ inoculated in the meat products could degrade nitrite and scavenge free radicals, and exhibited antioxidant activity and antibacterial effects (Ren et al., 2014). A previous report indicated that the Lactobacillus plantarum P2 isolated from traditional fermented sauerkraut had the ability to scavenge hydroxyl free radicals and superoxide free radicals and could degradate nitrite effectively (Chen et al., 2019). Zhang et al. (2020) found that the L. plantarum LPL-1 inhibited the growth of spoilage bacteria during fermentation and significantly reduced the content of histamine, putrescine, and cadaverine, and the total amount of biogenic amines of sausages. Guimarães et al. (2018) showed that the L. plantarum UM55 CFS could produce lactic acid along with other organic acids during fermentation, which has been confirmed to inhibit the growth of Aspergillus flavus. In addition, the Lactobacillus fermentum R6 was found to have antibacterial ability against the growth of Clostridium perfringens and its spores in chicken meat, so the strain could be used as a potential biopreservatives to prevent the contamination by $C$. perfringens in meat products (Li et al., 2017).

Some other studies pointed that the LAB had the effect of improving color in fermented sausages. The effect of different concentrations of L. fermentum on the color development of fermented sausages was studied, and the results showed that the strain contributed to the production of nitrosomyoglobin (Mb-NO) and $10^{8} \mathrm{CFU} / \mathrm{g}$ meat of the strain could produce the pink color similar to $60 \mathrm{mg} / \mathrm{kg}$ nitrite (Zhang et al., 2007). The research of Kawahara et al. (2006) showed that Lactobacillus sakei M32 could produce the red color with high redness ( $a^{*}$ value) and low yellowness ( $b^{*}$ value), and the color of the sample was similar to that of the control with nitrite added. Chen et al. (2016) isolated two strains of L. plantarum CMRC6 and L. sakei CMRC15 from traditional fermented pork and found that the two strains promoted nitrosation of myoglobin and produced the pink color in the sausages due to their nitrite reductase activity. In addition, LAB is usually used to improve the flavor and texture of fermented foods as a starter due to its acid production capacity. Moreover, LAB have many other functions, including regulating the intestinal flora, improving immunity, lowering cholesterol, etc. (Khalique et al., 2020; Saravanakumar et al., 2020). Therefore, the inoculation of LAB in foods has great value to improve food nutrition and protect human health (Sharafedtinov et al., 2013; Tu et al., 2018).

The above reports indicated that LAB have color development and antibacterial activity, so they might have the potential to replace nitrite in meat processing. However, no practical $\mathrm{LAB}$ strains have yet been found for industrial application as a complete substitute for nitrite. Therefore, the replacement for nitrite with $\mathrm{LAB}$ in meat products still requires in-depth exploration. The target of this study was to evaluate the positive effects of complete replacement of nitrite with the L. fermentum (CICC 21828) on the quality and safety of Chinese fermented sausages. The effects of the strain on $\mathrm{pH}$, color, nitrite, thiobarbituric acid reactive substances (TBARS), total volatile basenitrogen (TVB-N), metmyoglobin (Met-Mb), tyramine, free amino acid content, and sensory index have been studied.

\section{MATERIALS AND METHODS}

\section{Strains}

The LAB used in this experiment were L. fermentum (CICC 21828), which was provided by China Center of Industrial Culture Collection and preserved in the fermentation engineering laboratory, Qingdao Agricultural University.

\section{Sausage Manufacture}

The formulation of the sausages includes $75 \%$ lean pork meat, $25 \%$ pork back fat, $2.3 \% \mathrm{NaCl}, 3 \%$ sucrose, and $1 \% \mathrm{D}$-sodium erythorbate. The pork and pork casings were obtained from a local retailer in Qingdao (China). In addition, the $0.005 \%$ (50 mg/kg) $\mathrm{NaNO}_{2}$ was added in the control (Yoo et al., 2015), and $10^{10} \mathrm{CFU} / \mathrm{g}$ meat of the strain L. fermentum was inoculated in the sample to substrate $50 \mathrm{mg} / \mathrm{kg} \mathrm{NaNO}_{2}$. All the raw materials were chopped, mixed, and marinated at $4^{\circ} \mathrm{C}$ for $24 \mathrm{~h}$. The mixture was then stuffed in natural pork casings, fermented at $37^{\circ} \mathrm{C}$ in an incubator for $3 \mathrm{~h}$ with relative humidity $(\mathrm{RH})$ of $90 \%$, and then hung and dehydrated at $10^{\circ} \mathrm{C}$ for 20 days, with an $\mathrm{RH}$ of $70 \%$ according to our previous report (Zhu et al., 2020). Finally, the sausages were baked at $80^{\circ} \mathrm{C}$ for $1 \mathrm{~h}$, at $65^{\circ} \mathrm{C}$ for $8 \mathrm{~h}$, and then steamed at $100^{\circ} \mathrm{C}$ for $30 \mathrm{~min}$.

\section{pH and Chroma}

The sausages were minced to small pieces and were homogenized in $90 \mathrm{ml}$ of sterilized saline $(0.85 \%, \mathrm{w} / \mathrm{v})$ in a BagMixer for $90 \mathrm{~s}$, and then the $\mathrm{pH}$ was detected using a $\mathrm{pH}$ meter (FiveEasy Plus 28, Mettler Toledo, Shanghai, China) with a solid electrode. The sausages were sliced into slices about $2 \mathrm{~cm}$ and wrapped with a layer of film, and the chroma measurement was carried out with a Chroma Meter (CR-400, Konica Minolta Co., Tokyo, Japan). The values of lightness ( $L^{*}$ value), $a^{*}$ value, and $b^{*}$ value were recorded from different pieces of each sample.

\section{Nitrite Residual}

The nitrite residual was measured with the method of hydrochloride naphthodiamide according to a previous report (Zhang et al., 2007) with minor modification. The sausages were minced to small pieces and were pounded with mortar 
in $25 \mathrm{ml}$ of saturated borax solution. The volume was adjusted to $100 \mathrm{ml}$ with distilled water and boiled in a water bath for $15 \mathrm{~min}$, and then cooled to room temperature. After being filtered, the filtrate $(25 \mathrm{ml})$ was taken out and mixed with 4-aminobenzenesulfonic acid ( $2 \mathrm{ml}, 4 \mathrm{~g} / \mathrm{L})$ and $\mathrm{N}$-naphthylethylenediamine dihydrochloride $(1 \mathrm{ml}, 2 \mathrm{~g} / \mathrm{L})$ and set aside for $15 \mathrm{~min}$. The absorbance was measured at the wavelength of $538 \mathrm{~nm}$, and the nitrite residual was expressed with the following formula: $\mathrm{NaNO}_{2}=(\mathrm{C} \cdot 2000) /(\mathrm{M} \cdot \mathrm{V})$. Here, $\mathrm{C}$ is the sodium nitrite concentration of the sample obtained from the calibration curve, $\mathrm{M}$ is the sample weight, and $\mathrm{V}$ is the volume of the extraction solution.

\section{TBARS}

According to the method of Geeta and Yadav (2017) with slight modification, minced sausages (10 g) were homogenized with $50 \mathrm{ml}$ of trichloroacetic acid solution (7.5\% of trichloroacetic acid, $0.1 \%$ of EDTA, w/v), and then were filtered twice with three layers of filter paper. The filtrate was heated, and the distillate was collected. Then, $5 \mathrm{ml}$ of the distillate and $5 \mathrm{ml}$ of the TBA reagent $(0.02 \mathrm{~mol} / \mathrm{L}$, thiobarbituric acid $)$ were mixed and boiled in a water bath for $35 \mathrm{~min}$. After being cooled, the absorbance was detected at $530 \mathrm{~nm}$ with a spectrophotometer (UV-1,200, MAPADA, Shanghai, China), and the TBA value was expressed with the formula below:

$$
\text { TBA value }=\frac{50 \times(\mathrm{A}-\mathrm{B})}{\mathrm{m}}
$$

Here, $\mathrm{A}$ is the absorbance value of the sample solution, and $\mathrm{B}$ is the absorbance value of the blank.

\section{TVB-N}

The measurement of the TVB-N content was carried out according to the method of Wang et al. (2016) with some modifications. The sausages were minced to small pieces and were homogenized in $90 \mathrm{ml}$ of distilled water in a BagMixer for 90 $\mathrm{s}$, stirred for $30 \mathrm{~min}$, and filtered with three layers of filter paper. Then, $10 \mathrm{ml}$ of the filtrate was mixed with $10 \mathrm{ml}$ of $\mathrm{MgO}$ solution $(10 \mathrm{~g} / \mathrm{L})$ and distilled for $5 \mathrm{~min}$ in semimicro Kjeldahl bottle. The distillate was mixed with $10 \mathrm{ml}$ of boric acid solution $(10 \mathrm{~g} / \mathrm{L})$ and titrated with $0.01 \mathrm{~mol} / \mathrm{L} \mathrm{HCl}$. The content of the TVB-N was determined according to the consumption of hydrochloric acid.

\section{Amino Acid}

The measurement of amino acid content was carried out by the ninhydrin colorimetric method. The sausages were minced to small pieces and homogenized in $90 \mathrm{ml}$ of distilled water in a BagMixer for $90 \mathrm{~s}$, boiled in a water bath for $10 \mathrm{~min}$, cooled, and filtered. Then, $1 \mathrm{ml}$ of the filtrate was mixed with $1 \mathrm{ml}$ of citric acid buffer solution $(0.2 \mathrm{~mol} / \mathrm{L}, \mathrm{pH} 6.86)$ and $1 \mathrm{ml}$ of ninhydrin coloring solution in a test tube, and then the distilled water was added to make the total volume to $5.0 \mathrm{ml}$, shaken well, capped, and boiled in a water bath for $15 \mathrm{~min}$. After being cooled, the absorbance was measured at $568 \mathrm{~nm}$. Then, the content of amino acid was acquired by the standard curve. The standard curve was established through a series of concentrations of glycine standard solution $(10,20,30,40$, and $50 \mu \mathrm{g} / \mathrm{ml})$, and the processing steps were same as above.

\section{Met-Mb}

The Met-Mb measurement was carried out according to our previous report (Zhu et al., 2020). Sausage samples (10 g) were homogenized in $25 \mathrm{ml}$ of ice-cold phosphate buffer $(0.01 \mathrm{~mol} / \mathrm{L}$, $\mathrm{pH}$ 6.8), placed in the dark at $4^{\circ} \mathrm{C}$ for $1 \mathrm{~h}$, and then centrifuged at $4,000 \mathrm{~g}$ for $5 \mathrm{~min}$ at $4^{\circ} \mathrm{C}$. Finally, the supernatant was filtered with a $0.45-\mu \mathrm{m}$ nitrocellulose filter membrane. The Met-Mb content was determined by measuring the absorbance at 572,562 , 545 , and $525 \mathrm{~nm}$, respectively, using a spectrophotometer. The percentage of Met-Mb was determined with the formula below:

$$
\begin{aligned}
\text { Met-Mb\% }= & \left\{-2.51\left(\frac{A_{572}}{A_{525}}\right)+0.777\left(\frac{A_{562}}{A_{525}}\right)\right. \\
& \left.+0.8\left(\frac{A_{545}}{A_{525}}\right)+1.098\right\} \times 100 .
\end{aligned}
$$

\section{Biogenic Amine}

Sausage samples (1 g) were homogenized with $10 \mathrm{ml}$ of trichloroacetic acid solution (5\%,v/v) and extracted by ultrasonic extraction for $30 \mathrm{~min}$. After centrifugation, the extraction (1 ml) was taken out and reacted with $0.2 \mathrm{ml}$ of $\mathrm{NaOH}(2 \mathrm{~mol} / \mathrm{L})$ and $100 \mu \mathrm{l}$ of benzoyl chloride at $40^{\circ} \mathrm{C}$ for $30 \mathrm{~min}$. Then, the mixture was terminated with methanol and filtered with the membrane $(0.22 \mu \mathrm{m})$ for high-performance liquid chromatography (HPLC) to determine the biogenic amine content. HPLC analysis was carried out with Syncronis C18 column according to our previous report (Zhu et al., 2020). The temperature of the column was set as $35^{\circ} \mathrm{C}$ with the injection volume of $20 \mu \mathrm{l}$ and the UV detection wavelength of $254 \mathrm{~nm}$. The gradient mobile phase contained solvent $A$ and solvent $B$, and the procedure was started at a ratio of $70: 30(\mathrm{~A}: \mathrm{B})$ with a flow rate of $0.8 \mathrm{ml} / \mathrm{min}$; subsequently, solvent B increased gradually to $70 \%$ within $38 \mathrm{~min}$, and then maintained for $4 \mathrm{~min}$.

\section{Sensory Analysis}

Texture, flavor, slice, color, taste, sourness, and overall acceptability of the samples were evaluated according to a 10 -point scale from 1 to 10 (Nassu et al., 2003). The evaluation was performed by 10 people who had experience in sensory evaluation of fermented sausages. The samples were sliced to 5 -mm thickness and marked with three-digit random numbers. Then, the numbered slices were placed on white plates, and each sample was evaluated three times. Water and unsalted crackers were supplied to the panel to purify their palate between different samples.

\section{Statistical Analysis}

All measurements were performed in triplicate, respectively. The data analysis was carried out using IBM SPSS Statistics 23.0 (IBM, New York, NY, United States). For multiple comparisons between more than three sample groups, the one-way analysis of variance (ANOVA) was applied and the significant difference between the groups were analyzed with Duncan's multiple range tests. For the 
comparison between two sample groups, independent-sample $t$ test was employed. For both analysis methods, the significance was set at the level of $p<0.05$.

\section{RESULTS}

\section{$\mathrm{pH}$}

$\mathrm{pH}$ is an important indicator to monitor the fermentation process of fermented sausages. In Figure 1, $\mathrm{pH}$ of the control and the sample showed very little decrease at the beginning of the fermentation (within $0.5 \mathrm{~h}$ ). It might be because $L$. fermentum was in the growth phase of adapting to the new environment, resulting in low amount of lactic acid production. In the subsequent phase, the $\mathrm{pH}$ of the sample decreased sharply, which was much lower than that of the control. The sharp drop of the $\mathrm{pH}$ reflected that the anaerobic glycolysis increased and large amounts of lactic acid were produced in the growth of LAB (Chen et al., 2016). However, the $\mathrm{pH}$ of the sample was lower than the control during the whole fermentation process. For the sample sausages, when the $\mathrm{pH}$ dropped below 5.5, the speed of the $\mathrm{pH}$ decrease became slow. The phenomena might be attributed to the generation of non-protein nitrogen in the meat by proteolytic process, which would inhibit the decrease in $\mathrm{pH}$ through buffering the lactic acid (Chen et al., 2016). For the cathepsins will be activated and at $\mathrm{pH}$ 5.0-5.5 and accelerate the proteolysis (Visessanguan et al., 2003).

\section{Color Analysis}

According to Table 1, the $L^{*}$ value of the sample and the control all decreased throughout the ripening process, and the value of the sample was lower than that of the control at the end of the 20th day. The $a^{*}$ value of the sample and the control was also affected by ripening time and declined over time. However,

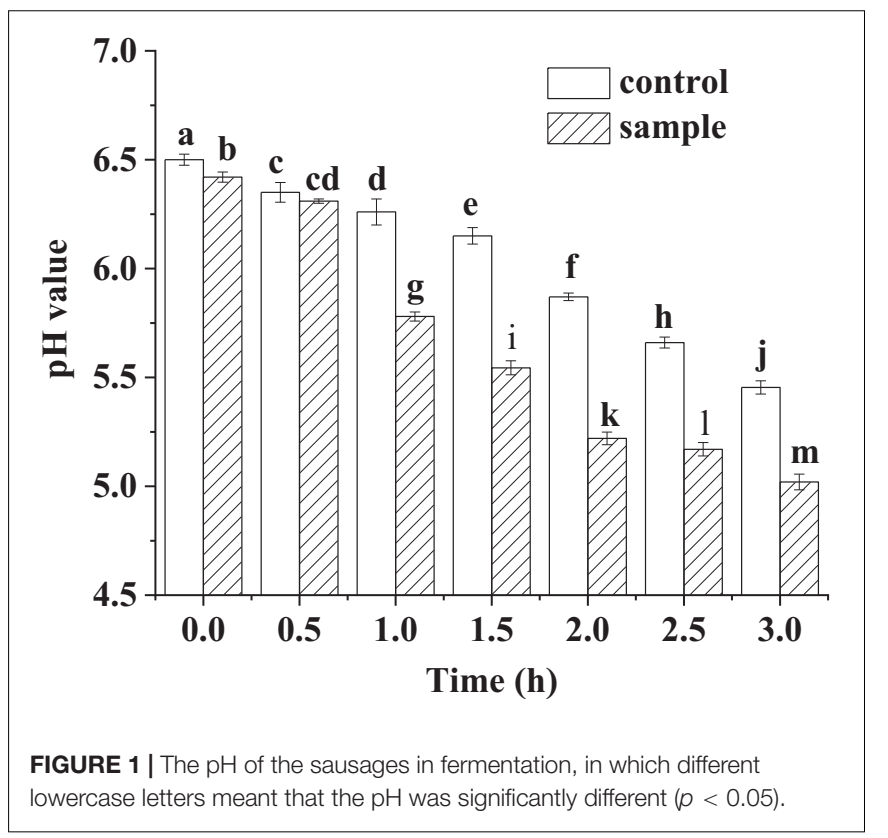

TABLE 1 | The color of the sausages during ripening period.

\begin{tabular}{|c|c|c|c|c|}
\hline & \multicolumn{2}{|c|}{ Control } & \multicolumn{2}{|c|}{ Sample } \\
\hline & $x$ & SD & $x$ & SD \\
\hline \multicolumn{5}{|l|}{$L^{*}$} \\
\hline Od & $59.78^{a A}$ & 2.15 & $54.23^{\mathrm{bA}}$ & 1.78 \\
\hline $5 d$ & $54.34^{\mathrm{aB}}$ & 1.73 & $50.45^{\mathrm{aB}}$ & 3.12 \\
\hline $10 d$ & $53.33^{a B}$ & 2.37 & $47.61^{\mathrm{bBC}}$ & 2.16 \\
\hline $15 d$ & $48.42^{\mathrm{aC}}$ & 2.09 & $48.55^{\mathrm{aBC}}$ & 1.40 \\
\hline $20 d$ & $47.27^{\mathrm{aC}}$ & 1.03 & $44.50^{\mathrm{bc}}$ & 1.14 \\
\hline \multicolumn{5}{|l|}{$a^{*}$} \\
\hline Od & $12.34^{\mathrm{aA}}$ & 1.14 & $10.71^{a A}$ & 0.67 \\
\hline $5 d$ & $13.67^{\mathrm{aA}}$ & 0.83 & $9.89^{b A}$ & 0.85 \\
\hline $10 d$ & $7.63^{a B}$ & 0.45 & $6.38^{a B}$ & 0.83 \\
\hline $15 d$ & $4.79^{\mathrm{aC}}$ & 1.15 & $5.18^{\mathrm{aBC}}$ & 0.48 \\
\hline $20 d$ & $5.26^{\mathrm{aC}}$ & 0.84 & $4.87^{\mathrm{aC}}$ & 0.56 \\
\hline \multicolumn{5}{|l|}{$b^{*}$} \\
\hline Od & $1.25^{\mathrm{aD}}$ & 0.31 & $0.44^{\mathrm{bc}}$ & 0.08 \\
\hline $5 d$ & $3.49^{\mathrm{aC}}$ & 0.56 & $0.56^{\mathrm{bBC}}$ & 0.11 \\
\hline $10 d$ & $4.12^{\mathrm{aC}}$ & 0.43 & $1.40^{\mathrm{bB}}$ & 0.67 \\
\hline $15 d$ & $5.25^{\mathrm{aB}}$ & 0.21 & $3.16^{\mathrm{bA}}$ & 0.78 \\
\hline $20 d$ & $6.22^{\mathrm{aA}}$ & 0.47 & $3.85^{\mathrm{bA}}$ & 0.32 \\
\hline
\end{tabular}

The superscripted letters a b c represent significantly different $(p<0.05)$ in the same line, and A B C represent significantly different $(p<0.05)$ in the same column.

at the 20th day, no significant difference $(p<0.05)$ in $a^{*}$ value was found between the sample and the control, indicating that the strain inoculation could produce the pink color in the sausages nitrite-free and could make the color stable. This further indicated that the strain had a similar color development ability to nitrite. Another study also reported that LAB had the color formation ability in meat products nitrite-free (Gao et al., 2014). In addition, LAB application level was important for color development, and $10^{8} \mathrm{CFU} / g$ inoculation of $L$. fermentum might develop the pink color similar to that produced by $60 \mathrm{mg} / \mathrm{kg}$ of nitrite (Zhang et al., 2007). The $b^{*}$ value of the sample and the control both increased during the ripening process, which indicated the oxidation of the sausages increased (Xiang et al., 2019). However, the value of the sample was much lower than that of the control in the whole ripening process, which indicated that the sample had good color and could inhibit lipid peroxidation (Xiang et al., 2019).

\section{The Nitrite Content}

In Figure 2, although no nitrite was added to the sample, small amounts $(3.22-2.07 \mathrm{mg} / \mathrm{kg})$ of nitrite were detected in the sample sausages during the ripening process. In other study, small amounts of nitrite were also detected in the sausages with L. fermentum inoculation and nitrite free (Zhang et al., 2007). The source of nitrite in the sample was not clear, which might be derived from the curing process of meat. Zhang et al. (2007) regarded that the source of nitrite might be tap water, because it was very difficult to produce tap water of nitrite free. The nitrite content of the two groups decreased during the ripening process. The reduction in nitrite content in the control attributed to the reaction between the nitrite and myoglobin, which resulted in 


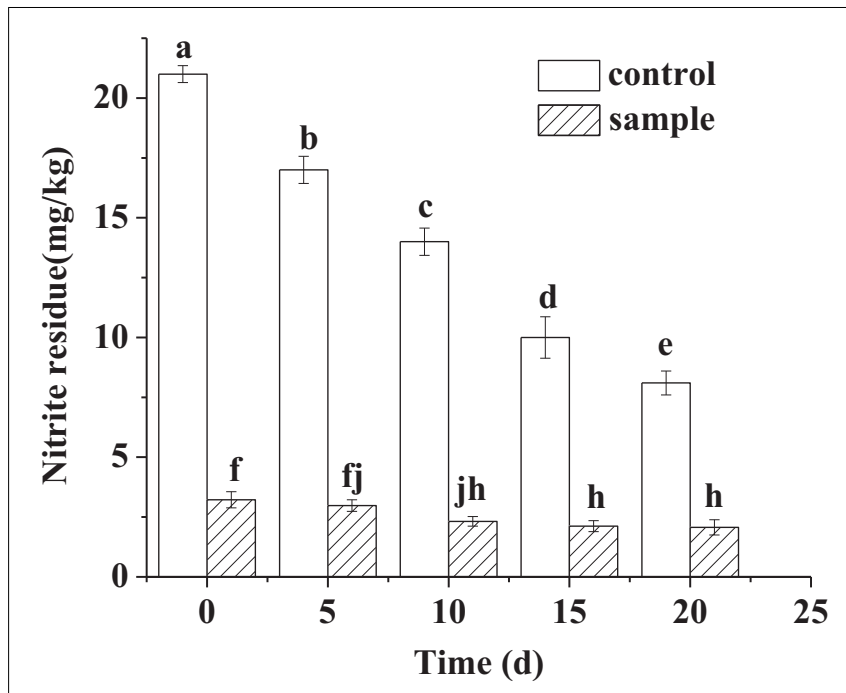

FIGURE 2 | The nitrite content of the sausages during ripening period, in which different lowercase letters meant that nitrite content was significantly different $(p<0.05)$.

the production of nitrosomyoglobin (Mb-NO). For the sample, it might be that the strain had nitrite degradation ability according to the previous report (Yoo et al., 2015). However, the content of the sample was always significantly lower $(p<0.05)$ than that of the control during all the ripening process. On the 30th day, the content of the sample was $2.07 \mathrm{mg} / \mathrm{kg}$, and that of the control was $8.1 \mathrm{mg} / \mathrm{kg}$.

\section{TBARS}

The TBA value reflects the extent of oxidation and rancidity of lipids in meat products. The TBA value of the two groups both increased constantly with extending ripening time (Figure 3 ). However, the TBA value of the control remained significantly higher $(p<0.05)$ than that of the sample during the whole ripening process (Figure 3). A previous study also had the similar result that the strain Lactobacillus pentosus inoculated in sausages had significantly inhibited the oxidation of lipids compared to the control (Sun et al., 2017). Although a previous report pointed out that nitrite could restrain the oxidation of lipids through different channels (Berardo et al., 2016), the result showed that the strain L. fermentum had stronger antioxidant capacity against lipids compared to the nitrite.

\section{TVB-N Content}

It could be seen from Figure 4 that the TVB-N content of the two groups increased continuously with time. TVB-N mainly reflects the degree of protein decomposition of meat products by microorganisms (Dabadé et al., 2015). Another study also regarded that TVB-N production might be due to the action of spoilage bacteria and endogenous enzymes (Song et al., 2011). There had been no significant difference $(p<0.05)$ between the sample and the control at the 20th day, indicating that the strain had a similar ability with that of nitrite in preventing protein decomposition from microorganisms and endogenous enzymes.

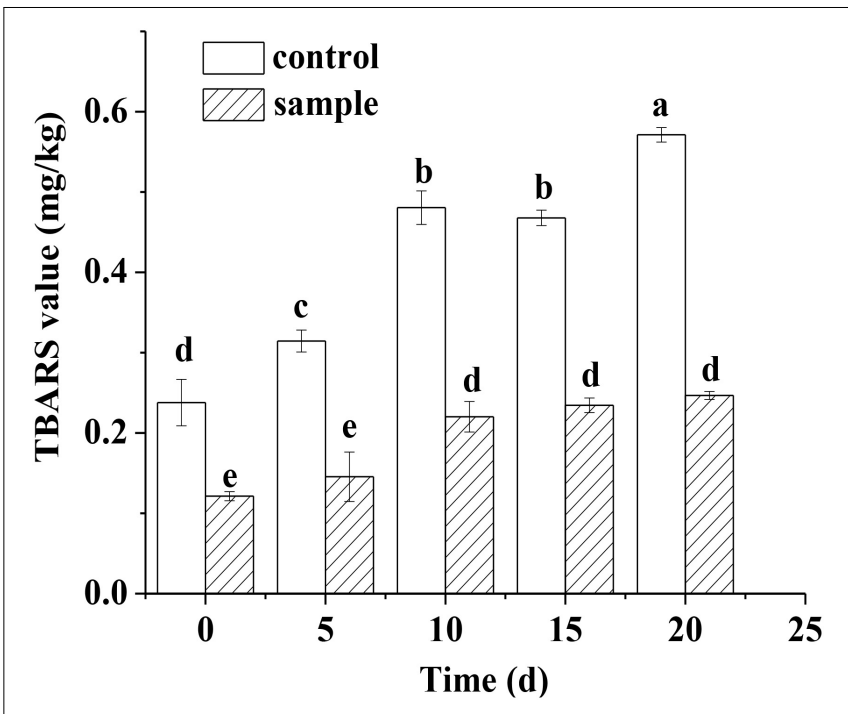

FIGURE 3 | The TBARS content of the sausages during ripening period, in which different lowercase letters meant that TBARS content was significantly different $(p<0.05)$.

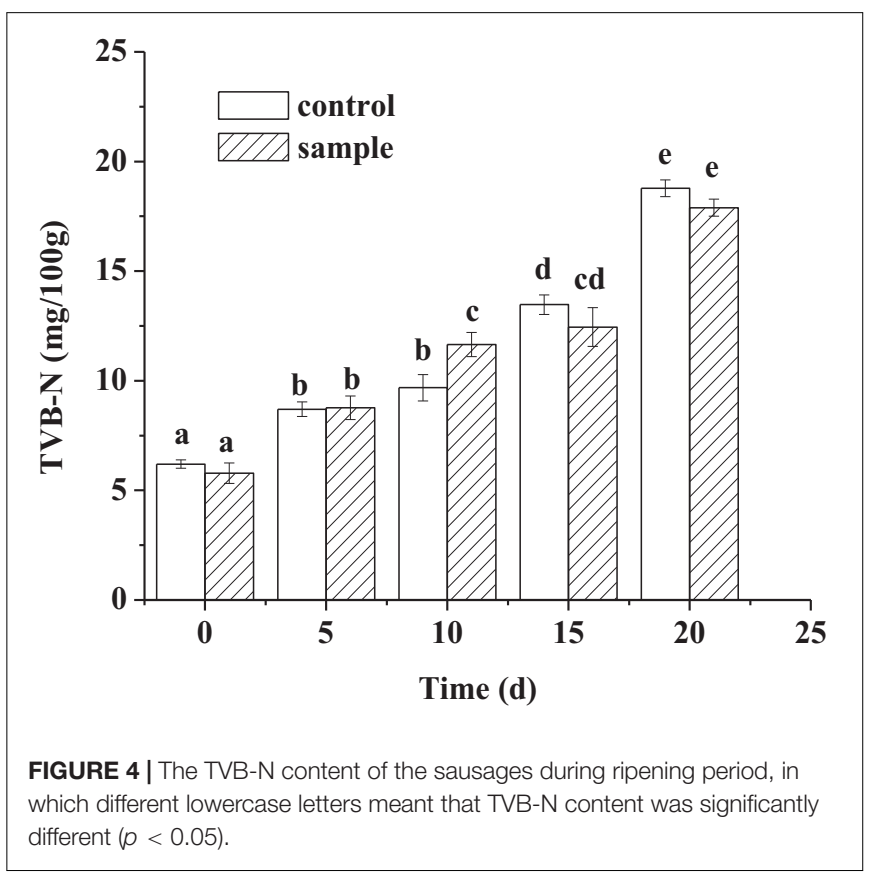

Hence, the strain had a similar ability as nitrite to reduce protein decomposition and microbial risks.

\section{Free Amino Acid and Met-Mb}

In Figure 5A, the content of total amino acids in the control was $18.38 \mathrm{mg} / 100 \mathrm{~g}$, while that of the sample was $53.19 \mathrm{mg} / 100 \mathrm{~g}$. In fermented sausages, meat proteins are first hydrolyzed into polypeptides by endogenous proteases, and further hydrolyzed into amino acids by microbial protease (Hu et al., 2021). The higher total amino acid contents in the sample inoculated with $\mathrm{LAB}$ might due to the proteolytic activity of the strain 

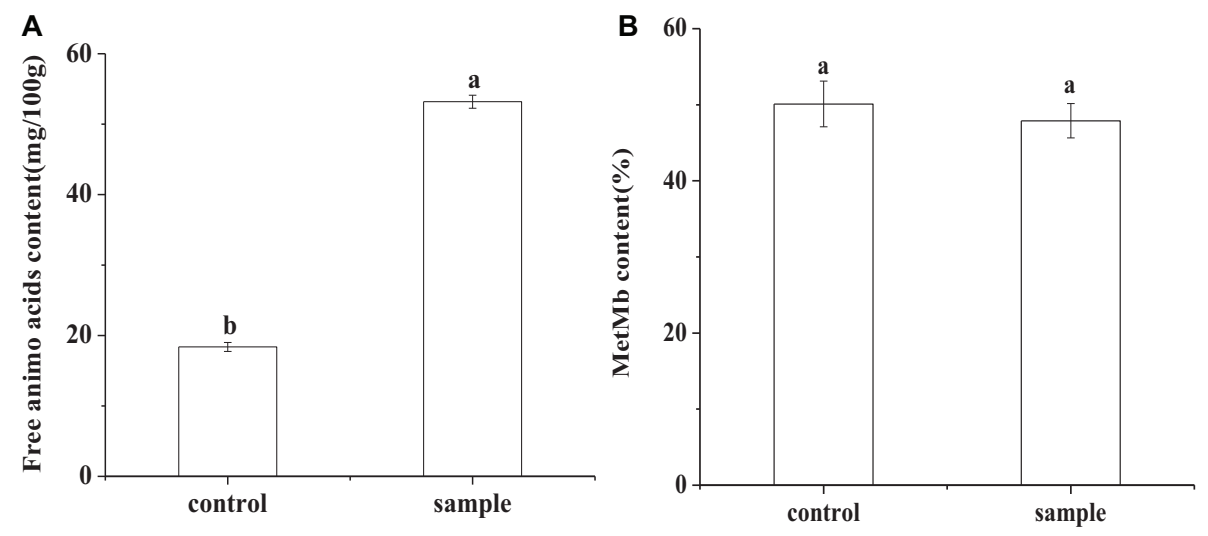

FIGURE 5 | The free amino acid content $\mathbf{( A )}$ and the Met-Mb content $\mathbf{( B )}$ of the sausages at the end of ripening period, in which different lowercase letters meant that amino acid content or Met-Mb content was significantly different $(p<0.05)$.

(Hu et al., 2021). The highest total amino acid concentration was also observed in a previous study of the sausages inoculated with L. plantarum MLK 14-2 (Yoo et al., 2015). Met-Mb was the oxidation product of myoglobin in meat products, which had a negative effect on color (Howes et al., 2019). There had been no significant difference $(p<0.05)$ in the content of Met-Mb between the control and the sample (Figure 5B), which indicated that replacing nitrite with $L$. fermentum did not cause an increase in Met-Mb content.

\section{The Content of Biogenic Amines}

Biogenic amines are usually found in a wide range of fermented foods and can bring health risks, in which histamine, tyramine, and phenethylamine are the primary cause of food poisoning. The European Union has established certain regulations on histamine with the maximum levels of $100 \mathrm{mg} / \mathrm{kg}$ (Sun et al., 2016). According to a previous report, the established maximum limits were $800 \mathrm{mg} / \mathrm{kg}$ for tyramine (Ercan et al., 2019) and $30 \mathrm{mg} / \mathrm{kg}$ for phenethylamine, respectively (Kandasamy et al., 2021). Seven kinds of biogenic amines including tyramine, putrescine, cadaverine, spermidine, tryptamine, phenylethylamine, and spermine were detected in the control (Table 2). For the sample, only tyramine, putrescine, cadaverine, spermidine, tryptamine, and spermine were detected, and no phenylethylamine was found. A previous report had suggested that the LAB used in the sausages might not contain phenylalanine decarboxylase activities, which resulted in no phenylethylamine produced (Pircher et al., 2007). Although the tyramine contents of sample was higher than the control, the contents of the two groups were all far below the specified limit $(800 \mathrm{mg} / \mathrm{kg})$. No histamine was detected both in the sample and the control, so the two group sausages had no histamine risk. In addition, the contents of spermidine and tryptamine decreased, and the contents of putrescine and cadaverine increased in the sample compared to the control. Hence, it is necessary to add other food additives together with the strain to inhibit the production of putrescine and cadaverine in future studies.

\section{Sensory Analysis}

Sensory analysis was performed by evaluating the texture, flavor, slice, color, taste, sourness, and overall acceptability of the sausages. Figure 6 shows that the scores of the sample were similar to the control in the texture, slice, and color. The scores of taste, flavor, and sourness of the sample were better than those of the control. The relatively high acidity might be attributed to the production of lactic acid during fermentation of the LAB, which brought better and proper sourness (Odutayo et al., 2020). The better taste and flavor of the sample might be because the fermentation of the LAB could produce a variety of flavor components (Hu et al., 2019). Moreover, the inoculation of LAB could inhibit the lipid oxidation of the sausages, which prevents the unfavorite flavor (Hu et al., 2019). The result was consistent with the TBARS analysis (Figure 3) that the L. fermentum had stronger antioxidant capacity against lipid oxidation compared to the nitrite. Therefore, the overall acceptability of the sausages was better than the control, which was similar to a previous report that the $\mathrm{LAB}$ inoculation could make sausage quality better (Bachtarzi et al., 2020).

TABLE 2 | The biogenic amine content of the sausages at the end of ripening period.

\begin{tabular}{lcc}
\hline Biogenic amine $(\mathbf{m g} / \mathbf{k g})$ & \multicolumn{2}{c}{ Sausage } \\
\cline { 2 - 3 } & Control & Sample \\
\hline Tyramine & $78.24^{\mathrm{b}}$ & $116.62^{\mathrm{a}}$ \\
Putrescine & $6.60^{\mathrm{b}}$ & $85.27^{\mathrm{a}}$ \\
Cadaverine & $163.30^{\mathrm{b}}$ & $462.13^{\mathrm{a}}$ \\
Spermidine & $4.53^{\mathrm{a}}$ & $2.50^{\mathrm{b}}$ \\
Tryptamine & $5.88^{\mathrm{a}}$ & $0.19^{\mathrm{b}}$ \\
Phenylethylamine & 6.15 & $\mathrm{ND}$ \\
Spermine & $28.68^{\mathrm{a}}$ & $31.21^{\mathrm{a}}$ \\
Histamine & $\mathrm{ND}$ & $\mathrm{ND}$
\end{tabular}

The superscripted letters a b c represent significantly different $(p<0.05)$ in the same line. 


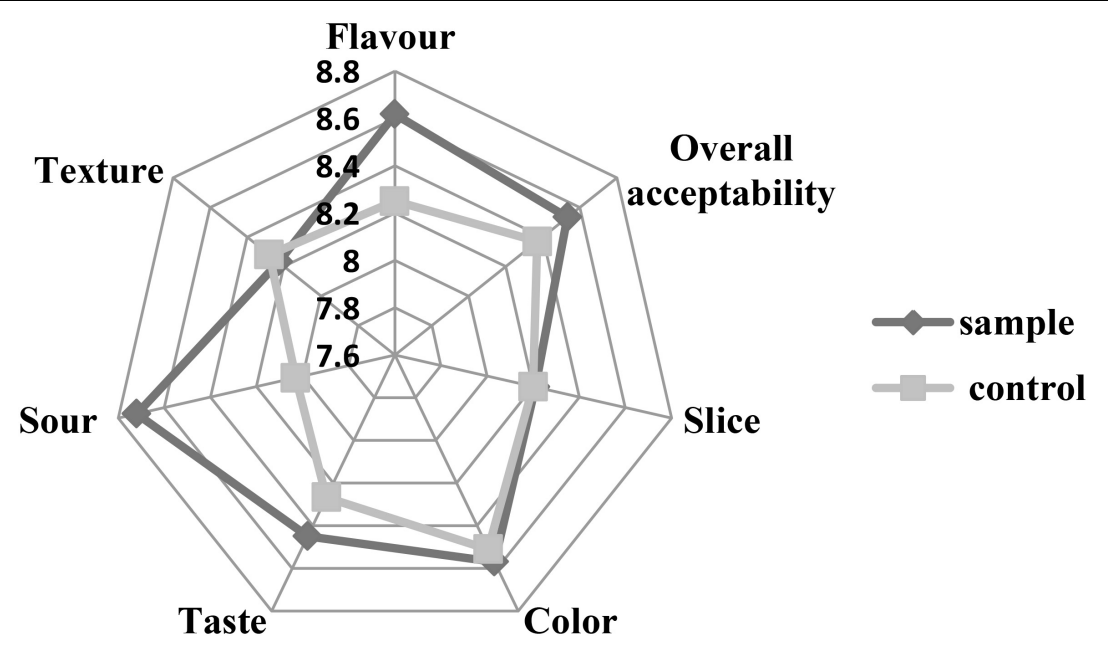

FIGURE 6 | The sensory analysis of the sausages.

\section{DISCUSSION}

The low $\mathrm{pH}$ of the sample sausages fermented by L. fermentum (Figure 1) signified that the acidification of the sample was much stronger than that of the control fermented spontaneously (Wang et al., 2013). The $\mathrm{pH}$ sharp drop of the samples might induce conformational changes of proteins and result in acid-induced gelation (Zeng et al., 2013). In addition, low $\mathrm{pH}$ might decrease the risk of food-borne pathogens and improve the safety of the sausages (Gao et al., 2014), which would extend shelf life of the sausages (Sun et al., 2017). Because the growth of food borne pathogens and spoilage bacteria would be inhibited under acidic conditions, the spoilage of the sausage might be suppressed.

There had no significance in $a^{*}$ value $(p>0.05)$ between the sample and the control at the 20th day, which indicated that the $L$. fermentum had the color formation ability in meat products nitrite-free. The color formation ability might be because some LAB had nitric oxide synthase (NOS) activity, resulting in the production of $\mathrm{NO}$, which reacted with myoglobin $(\mathrm{Mb})$ in the inoculated sausages and generated the pink product of $\mathrm{Mb}-\mathrm{NO}$ (Zhu et al., 2019). Compared to the control, the much lower $b^{*}$ value of the sample reflected that the strain inoculation could inhibit lipid peroxidation. The oxidation might result in the oxidation of $\mathrm{Fe}^{2+}$, which would cause the color of the sausages to appear brown (Ganhão et al., 2010). The color formation capacity and the antilipid oxidation ability of the strain indicated that the strain had the potential to replace nitrite for color development. In addition, nitrite can react with secondary amines to form nitrosamines (Sun et al., 2017), which has carcinogenic effects to humans. In this study, replacing nitrite with the L. fermentum significantly reduced the content of nitrite compared to the control (Figure 2). Therefore, replacing nitrite with the strain of L. fermentum decreased the residual of nitrite from the source and eliminate the carcinogenic risk of nitrite.

Lipid peroxidation will produce some harmful substances; therefore, the antioxidant function of the additives and the reduction of TBA value are very important (Gao et al., 2014). The strong antioxidant capacity of the strain $L$. fermentum against lipid oxidation (Figure 3) might be because the strain could scavenge free radical effectively (Chen et al., 2019). The sausage quality could be improved by preventing fat oxidation (Hu et al., 2019). In addition, the strain could inhibit the production of TVB-N (Figure 4), which is probably because the acidification process inhibited the growth of bacteriaceae and other bacteria (Sun et al., 2017). Because some microorganisms could secrete proteases, which might hydrolyze protein to produce nitrogen compounds including TVB-N (Sun et al., 2017).

The highest total amino acid concentration in the sample (Figure 5A) might be attributed to the strain hydrolyzed proteins forming the necessary amino acids required for growth (Hou et al., 2015). Amino acids play a key role in enhancing the flavor and increasing the nutrition of the sausages. The similar Met$\mathrm{Mb}$ content in the control and the sample (Figure 5B) indicated that the strain L. fermentum had a similar ability as nitrite against $\mathrm{Mb}$ oxidation and avoided excessive production of Met-Mb. This ability might be due to the presence of Met-Mb reductase in the strain, which reduced Met-Mb to $\mathrm{Mb}$ and further produced Mb-NO (Zhu et al., 2019).

Small amounts of biogenic amines have important physiological effects on the human body, but if accumulated excessively, it would be life-threatening (Silla Santos, 1996). The results showed that substituting nitrite with the strain reduced the species of harmful biological amines and no phenylethylamine was detected in the sample (Table 2). Histamine is the most harmful amine and is closely related to human health problems (Nie et al., 2014). No histamine was detected in the sample, which might be because LAB could inhibit the growth of Enterobacteriaceae, which have been proven to be able to produce large amounts of histamine (Pircher et al., 2007). Even so, if other additives together with the strain were added to inhibit the production of tyramine, putrescine, and cadaverine, the biogenic amines risk could be reduced thoroughly, and the quality and safety of sausages would be greatly improved. 
The quality of meat products depends on consumer' appreciation and acceptance. Therefore, sensory analysis is very important for meat products according to the sensory evaluation test. The inoculation of the L. fermentum enhanced the taste, flavor, sourness, and overall acceptability of the sample sausages (Figure 6). The higher acidification of the sample could inhibit the growth of the pathogens and spoilage bacteria and make the LAB dominate the microflora (Xiao et al., 2020), which further enhanced the flavor of the sausages. On the other hand, the previous report indicated that there was a synergistic effect between sourness and saltiness, and the sourness enhanced the salty taste of the sausages, thereby giving the sausages a better taste (Hu et al., 2021). In addition, the strain has strong antioxidant capacity against lipid oxidation (Figure 3), which might prevent the rancid flavor of lipids oxidation.

\section{CONCLUSION}

This study explored the positive effects of complete replacement of nitrite with the strain L. fermentum on the quality and safety of Chinese fermented sausages and evaluated the risk of this strain. The results revealed that the strain reduced the $\mathrm{pH}$ and the food-borne pathogens risk, and accelerated the acidification process and gelation formation of the sausages. In addition, the strain could produce the pink color similar to $50 \mathrm{mg} / \mathrm{kg}$ nitrite, significantly reducing the residual risk of nitrite in the sausages. In addition, the strain prevented fat oxidation, protein decomposition, and $\mathrm{Mb}$ oxidation and increased the free amino

\section{REFERENCES}

Bachtarzi, N., Speciale, I., Kharroub, K., Castro, C. D., Ruiz, L., and Ruas-Madiedo, P. (2020). Selection of exopolysaccharide-producing Lactobacillus plantarum (lactiplantibacillus plantarum) isolated from algerian fermented foods for the manufacture of skim-milk fermented products. Microorganisms 8:1101. doi: 10.3390/microorganisms8081101

Berardo, A., De Maere, H., Stavropoulou, D. A., Rysman, T., Leroy, F., and De Smet, S. (2016). Effect of sodium ascorbate and sodium nitrite on protein and lipid oxidation in dry fermented sausages. Meat Sci. 121, 359-364. doi: 10.1016/j.meatsci.2016.07.003

Chen, X., Li, J., Zhou, T., Li, J., Yang, J., Chen, W., et al. (2016). Two efficient nitritereducing Lactobacillus strains isolated from traditional fermented pork (Nanx Wudl) as competitive starter cultures for Chinese fermented dry sausage. Meat Sci. 121, 302-309. doi: 10.1016/j.meatsci.2016.06.007

Chen, Y., Li, Q., Xia, C., Yang, F., Xu, N., Wu, Q., et al. (2019). Effect of selenium supplements on the antioxidant activity and nitrite degradation of lactic acid bacteria. World J. Microb. Bio. 35, 1-13. doi: 10.1007/s11274-019-2609-x

Dabadé, D. S., den Besten, H. M. W., Azokpota, P., Nout, M. J. R., Hounhouigan, D. J., and Zwietering, M. H. (2015). Spoilage evaluation, shelf-life prediction, and potential spoilage organisms of tropical brackish water shrimp (Penaeus notialis) at different storage temperatures. Food Microbiol. 48, 8-16. doi: 10. 1016/j.fm.2014.11.005

Drabik-Markiewicz, G., Dejaegher, B., De Mey, E., Kowalska, T., Paelinck, H., and Vander Heyden, Y. (2011). Influence of putrescine, cadaverine, spermidine or spermine on the formation of $\mathrm{N}$-nitrosamine in heated cured pork meat. Food Chem. 126, 1539-1545. doi: 10.1016/j.foodchem.2010.11.149

Ercan, S. Ş, Soysal, Ç, and Bozkurt, H. (2019). Biogenic amine contents of fresh and mature kashar cheeses during refrigerated storage. Food Health 5, 19-29. doi: 10.3153/FH19003 acid content. The strain reduced species of biogenic amines, and decreased the phenylethylamine, spermidine, and tryptamine risk. Some other additives that can inhibit the production of tyramine, putrescine, and cadaverine are necessary to replace nitrite with the strain $L$. fermentum together in the future research. Therefore, the strain has the potential to replace nitrite to produce healthier sausages.

\section{DATA AVAILABILITY STATEMENT}

The original contributions presented in the study are included in the article/supplementary material, further inquiries can be directed to the corresponding author/s.

\section{AUTHOR CONTRIBUTIONS}

YX was responsible for the method, data acquisition, curation, and analysis. YZ designed the study and drafted the original manuscript. Both authors contributed to the article and approved the submitted version.

\section{FUNDING}

The research was financially supported by the National Natural Science Foundation of China (No. 31501512) and the Shandong Province Key Research and Development Plan-Special Plan for Medical Food (No. 2019YYSP023).

Ganhão, R., Morcuende, D., and Estévez, M. (2010). Protein oxidation in emulsified cooked burger patties with added fruit extracts: influence on colour and texture deterioration during chill storage. Meat Sci. 85, 402-409. doi: 10.1016/j.meatsci. 2010.02.008

Gao, Y. R., Li, D. P., and Liu, X. Y. (2014). Bacteriocin-producing Lactobacillus sakei $\mathrm{C} 2$ as starter culture in fermented sausages. Food Control 35, 1-6. doi: 10.1016/j.foodcont.2013.06.055

Geeta, and Yadav, A. S. (2017). Antioxidant and antimicrobial profile of chicken sausages prepared after fermentation of minced chicken meat with Lactobacillus plantarum and with additional dextrose and starch. LWT Technol. 77, 249-258. doi: 10.1016/j.lwt.2016.11.050

Guimarães, A., Santiago, A., Teixeira, J. A., Venâncio, A., and Abrunhosa, L. (2018). Anti-aflatoxigenic effect of organic acids produced by Lactobacillus plantarum. Int. J. Food Microbiol. 264, 31-38. doi: 10.1016/j.ijfoodmicro.1 0.025

Hou, J. C., Liu, F., Ren, D. X., Han, W. W., and Du, Y. O. (2015). Effect of culturing conditions on the expression of key enzymes in the proteolytic system of lactobacillus bulgaricus. J. Zhejiang Univ. Sci. B 16, 317-326. doi: 10.1631/ jzus.B1400230

Howes, B. D., Milazzo, L., Droghetti, E., Nocentini, M., and Smulevich, G. (2019). Addition of sodium ascorbate to extend the shelf-life of tuna meat fish: a risk or a benefit for consumers? J. Inorg. Biochem. 200:110813. doi: 10.1016/j.jinorgbio. 2019.110813

Hu, Y. Y., Chen, Q., Wen, R. X., Wang, Y., Qin, L. G., and Kong, B. (2019). Quality characteristics and flavor profile of Harbin dry sausages inoculated with lactic acid bacteria and Staphylococcus xylosus. LWT Technol. 114:108392. doi: 10.1016/j.lwt.2019.108392

Hu, Y. Y., Li, Y. J., Zhu, J. M., Kong, B. H., Liu, Q., and Chen, Q. (2021). Improving the taste profile of reduced-salt dry sausage by inoculating different lactic acid bacteria. Food Res. Int. 145:110391. doi: 10.1016/j.foodres.2021.110391 
Kandasamy, S., Yoo, J., Yun, J., Kang, H. B., and Ham, J. S. (2021). Quantitative analysis of biogenic amines in different cheese varieties obtained from the korean domestic and retail markets. Metabolites 11:31. doi: 10.3390/ metabo11010031

Kawahara, Y., Nakamura, M., Sakagami, I., and Suzuki, Y. (2006). Bright red color formation of cooked pork loin cured with lactic acid bacteria starter culture without adding nitrite during low-temperature storage. Food Sci. Tech. Res. 12, 101-107. doi: 10.3136/fstr.12.101

Khalique, A., Zeng, D., Shoaib, M., Wang, H., and Ni, X. (2020). Probiotics mitigating subclinical necrotic enteritis (sne) as potential alternatives to antibiotics in poultry. AMB Express 10:50. doi: 10.1186/s13568-020-00989-6

Li, P., Jia, S., Zhou, C., Fang, H., and Chen, C. (2017). Protective role of Lactobacillus fermentum R6 against Clostridium perfringens in vitro and in chicken breast meat under temperature abuse conditions. Innov. Food Sci. Emerg. 41, 117-123. doi: 10.1016/j.ifset.2017.03.001

Molognoni, L., Daguer, H., Motta, G. E., Merlo, T. C., and Lindner, J. D. D. (2019). Interactions of preservatives in meat processing: formation of carcinogenic compounds, analytical methods, and inhibitory agents. Food Res. Int. 125:108608. doi: 10.1016/j.foodres.2019.108608

Nassu, R. T., Goncalves, L. A. G., Silva, M., and Beserra, F. J. (2003). Oxidative stability of fermented goat meat sausage with different levels of natural antioxidant. Meat Sci. 63, 43-49. doi: 10.1016/S0309-1740(02)00051-7

Nie, X., Zhang, Q., and Lin, S. (2014). Biogenic amine accumulation in silver carp sausage inoculated with Lactobacillus plantarum plus Saccharomyces cerevisiae. Food Chem. 153, 432-436. doi: 10.1016/j.foodchem.2013.12.093

Odutayo, O. E., Omonigbehin, E. A., Olawole, T. D., Ogunlana, O. O., and Afolabi, I. S. (2020). Fermentation enhanced biotransformation of compounds in the kernel of Chrysophyllum albidum. Molecules 25:6021. doi: 10.3390/ molecules25246021

Pircher, A., Bauer, F., and Paulsen, P. (2007). Formation of cadaverine, histamine, putrescine and tyramine by bacteria isolated from meat, fermented sausages and cheeses. Eur. Food Res. Technol. 226, 225-231. doi: 10.1007/s00217-006-0530-7

Ren, D., Li, C., Qin, Y., Yin, R., Du, S., Ye, F., et al. (2014). In vitro evaluation of the probiotic and functional potential of Lactobacillus strains isolated from fermented food and human intestine. Anaerobe 30, 1-10. doi: 10.1016/ j.anaerobe.2014.07.004

Silla Santos, M. H. (1996). Biogenic amines: their importance in foods. Int. J. Food Microbiol. 29, 213-231. doi: 10.1016/0168-1605(95)00032-1

Saravanakumar, K., Sathiyaseelan, A., Mariadoss, A., Chelliah, R., and Wang, M. H. (2020). Lactobacillus rhamnosus GG and biochemical agents enrich the shelf life of fresh-cut bell pepper (capsicum annuum 1. var. grossum (1.) sendt). Foods 9:1252. doi: 10.3390/foods9091252

Sharafedtinov, K. K., Plotnikova, O. A., Alexeeva, R. I., Sentsova, T. B., and Mikelsaar, M. (2013). Hypocaloric diet supplemented with probiotic cheese improves body mass index and blood pressure indices of obese hypertensive patients-a randomized double-blind placebo-controlled pilot study. Nutr. J. 12:138. doi: 10.1186/1475-2891-12-138

Song, Y., Liu, L., Shen, H., You, J., and Luo, Y. (2011). Effect of sodium alginatebased edible coating containing different anti-oxidants on quality and shelf life of refrigerated bream (Megalobrama amblycephala). Food Control 22, 608-615. doi: 10.1016/j.foodcont.2010.10.012

Sun, F., Kong, B., Chen, Q., Han, Q., and Diao, X. (2017). N-nitrosoamine inhibition and quality preservation of Harbin dry sausages by inoculated with Lactobacillus pentosus, Lactobacillus curvatus and Lactobacillus sake. Food Control 73, 1514-1521. doi: 10.1016/j.foodcont.2016.11.018

Sun, X., Zhou, K., Gong, Y., Zhang, N., Yang, M., Qing, D. D., et al. (2016). Determination of biogenic amines in Sichuan-style spontaneously fermented sausages. Food Anal. Methods 9, 2299-2307. doi: 10.1007/s12161-016-0417-6

Tu, P., Bian, X., Liang, C., Gao, B., Ru, H., Knobloch, T. J., et al. (2018). Characterization of the functional changes in mouse gut microbiome associated with increased Akkermansia muciniphila population modulated by dietary black raspberries. ACS Omega 3, 10927-10937. doi: 10.1021/acsomega.8b00064

Visessanguan, W., Benjakul, S., and An, H. (2003). Purification and characterization of cathepsin L in arrowtooth flounder (Atheresthes stomias) muscle. Comp. Biochem. Physiol. B Biochem. Mol. Biol. 134, 477-487. doi: 10.1016/S1096-4959(02)00293-2

Wang, X. H., Ren, H. Y., Liu, D. Y., Zhu, W. Y., and Wang, W. (2013). Effects of inoculating Lactobacillus sakei starter cultures on the microbiological quality and nitrite depletion of Chinese fermented sausages. Food Control 32, 591-596. doi: 10.1016/j.foodchem.2016.04.036

Wang, X. H., Ren, H. Y., Wang, W., and Xie, Z. J. (2016). Effects of a starter culture on histamine reduction, nitrite depletion and oxidative stability of fermented sausages. J. Food Saf. 36, 195-202. doi: 10.1111/jfs.12227

Xiang, R., Cheng, J. R., Zhu, M. J., and Liu, X. M. (2019). Effect of mulberry (Morus alba) polyphenols as antioxidant on physiochemical properties, oxidation and bio-safety in Cantonese sausages. LWT Food Sci. Technol. 116:108504. doi: 10.1016/j.lwt.2019.108504

Xiao, Y., Liu, Y., Chen, C., Xie, T., and Li, P. (2020). Effect of Lactobacillus plantarum and staphylococcus xylosus on flavour development and bacterial communities in chinese dry fermented sausages. Food Res. Int. 135:109247. doi: 10.1016/j.foodres.2020.109247

Yoo, S. A., Na, C. S., Park, S. E., Seo, S. H., and Son, H. S. (2015). Characterization of fermented sausages using Lactobacillus plantarum MLK 14-2 as starter culture. J. Korean Soc. Appl. Biol. Chem. 58, 349-358. doi: 10.1007/s13765-015-0052-8

Zeng, X. F., Xia, W. S., Jiang, Q. X., and Yang, F. (2013). Effect of autochthonous starter cultures on microbiological and physico-chemical characteristics of Suan yu, a traditional Chinese low salt fermented fish. Food Control 33, 344-351. doi: 10.1016/j.foodcont.2013.03.001

Zhang, X., Kong, B., and Xiong, Y. L. (2007). Production of cured meat color in nitrite-free Harbin red sausage by Lactobacillus fermentum fermentation. Meat Sci. 77, 593-598. doi: 10.1016/j.meatsci.2007.05.010

Zhang, Y., Qin, Y., Wang, Y., Huang, Y., Li, P., and Li, P. (2020). Lactobacillus plantarum LPL-1, a bacteriocin producing strain, changed the bacterial community composition and improved the safety of low-salt fermented sausages. LWT Food Sci. Technol. 128:109385. doi: 10.1016/j.lwt.2020.109385

Zhu, Y., Wang, P., Guo, L., Wang, J., Han, R., Sun, J., et al. (2019). Effects of partial replacement of sodium nitrite with Lactobacillus pentosus inoculation on quality of fermented sausages. J. Food Process. Preserv. 43:e13932. doi: 10. $1111 /$ jfpp. 13932

Zhu, Y. L., Guo, L. P., and Yang, Q. L. (2020). Partial replacement of nitrite with a novel probiotic Lactobacillus plantarum on nitrate, color, biogenic amines and gel properties of Chinese fermented sausages. Food Res. Int. 137:109351. doi: 10.1016/j.foodres.2020.109351

Conflict of Interest: The authors declare that the research was conducted in the absence of any commercial or financial relationships that could be construed as a potential conflict of interest.

Publisher's Note: All claims expressed in this article are solely those of the authors and do not necessarily represent those of their affiliated organizations, or those of the publisher, the editors and the reviewers. Any product that may be evaluated in this article, or claim that may be made by its manufacturer, is not guaranteed or endorsed by the publisher.

Copyright (c) $2021 \mathrm{Xu}$ and Zhu. This is an open-access article distributed under the terms of the Creative Commons Attribution License (CC BY). The use, distribution or reproduction in other forums is permitted, provided the original author(s) and the copyright owner(s) are credited and that the original publication in this journal is cited, in accordance with accepted academic practice. No use, distribution or reproduction is permitted which does not comply with these terms. 